\title{
¿RE/POSICIÓN? DE “TRES MARÍAS Y UNA ROSA”: TRES DÉCADAS PARA A/BORDAR LA RESISTENCIA
}

\author{
Yael Zaliasnik \\ Universidad de Santiago de Chile \\ yzaliasnik@hotmail.com
}

\section{RESUMEN/ ABSTRACT}

Este trabajo busca indagar en las condiciones y repercusiones de volver a poner en escena una obra emblemática del teatro de los años de dictadura en Chile, "Tres Marías y una Rosa", tres décadas después y sin ninguna modificación significativa. En palabras de Raymond Williams, ¿qué es lo residual, lo dominante, lo emergente? ¿Qué se gana/pierde con esta reposición? ¿Cómo se percibe (se "lee")? ¿Existen imágenes sociales residuales de la dictadura? ¿Qué representaba la obra hace 30 años; ha cambiado esto hoy? Ineluctablemente, estas interrogantes nos llevan al tema de las arpilleras y las arpilleristas, a nuestro entender, central en la obra, pero que es evadido y olvidado como movimiento de resistencia, al no profundizarse en él en este nuevo montaje.

PalabRAs ClaVE: resistencia, memoria, "performance”, agenciamiento, identidad.

The present work explores the conditions and repercussions of staging anew an emblematic play of the dictatorship era in Chile: "Tres Marias y una Rosa," three decades after that period, and without significant modifications. In the words of Raymond Williams, what's the residual, the dominant, the emergent? What is won/lost in this re-staging? How is it perceived ("read")? Are there still residual social images from the dictatorship? What did the play represent 30 years ago, and has that changed today? Inevitably, these questions lead us to the issue of the Chilean textile craft of the "arpilleras" and the women artisans who made these ("arpilleristas"), to our understanding, central to the play, but avoided and forgotten as a resistance movement, as it is not treated in depth in its current staging.

KEY WORDS: Resistance, memory, performance, agency, identity. 
"El año cobraba un mal aspecto. Muy pocos se daban cuenta de ello, pero la ciudad no era la misma. No estaba demostrado que los objetos pintaran en los pisos un cabal equivalente en sombras. Más aún, las sombras tenian una evidente propensión a querer desprenderse de las cosas, como si las cosas tuvieran mala sombra. Una súbita proliferación de musgos ennegrecía los tejados. Apremiadas por la humedad nueva las columnas de los soportales se desconchaban en una noche" (Carpentier 129).

Chejov lamentaba no poder impedir la producción y traducción de sus obras en el extranjero, porque ponía en tela de juicio la posibilidad de transferir una pieza de teatro de una cultura a otra. Dudaba, por ejemplo, de que los espectadores que no fueran rusos pudieran entender a cabalidad el significado de la venta de la finca en "El jardín de los cerezos". A su posición extrema se enfrenta una gama muy amplia de otros puntos de vista que sí creen en la posibilidad de poner en escena una obra en otra época, lugar, situación. De hecho, es una práctica recurrente el remontaje de piezas consideradas "clásicas", colocando el énfasis más que en el contexto original de su producción, en los valores "universales" que ellas transmiten. Raúl Osorio, quien dirigió la puesta en escena original de "Tres Marías y una Rosa", estrenada a fines de julio de 1979, en plena dictadura en Chile, está a cargo también hoy, tres décadas después, de su reposición en el Teatro Nacional, donde ejerce como director artístico desde el $2001^{1}$. Para ésta -en la cual incluso tres de las cuatro actrices que participan ni siquiera habían nacido cuando se estrenó por primera vez la obra-, mantuvo prácticamente intacto el texto primigenio (solo agregó algunos cortes distintos a la estructura dramática), porque él sostiene que "Tres Marías y una Rosa", efectivamente, pertenece a los "clásicos" del teatro chileno, lo que explica de la siguiente manera:

Esta es una obra que, junto con otras, forman parte de las obras clásicas del teatro chileno. Estas han sucedido en algún momento en la historia del teatro del país y en la historia de la sociedad y han tenido una presencia muy importante, no sólo artística, sino que social y política. Son portadoras de voces que hablan de lo que sucedía en

1 La obra nació fruto del trabajo colectivo de cuatro actrices del Taller de Investigación Teatral (TIT) -Myriam Palacios, Lucy Jiménez, Soledad Alonso y Loreto Valenzuela- con su director, Raúl Osorio, quienes estuvieron cerca de dos años asistiendo a los talleres de arpilleristas que funcionaban al alero de la Vicaría de la Solidaridad. A este trabajo se sumó posteriormente el dramaturgo David Benavente, quien escribió el texto. 
ese momento de la historia de Chile, y han estado construidas de tal manera, en términos de estructura, de construcción de personajes, de la calidad artística que tienen, tanto por su texto como por la puesta en escena en el momento que correspondió, que permanecen en el tiempo, traspasan el tiempo, no solamente por las temáticas, sino por la factura. Hoy esas obras pueden darse en el presente y tener una vigencia que nos transmite mensajes de otros tiempos de la historia de nuestro país pero que también nos remiten a situaciones, temas y sentidos que tienen que ver con el presente, no solamente con el pasado. Nos recuerdan el pasado, pero nos hacen conscientes del presente $^{2}$.

Osorio asegura que si bien "el mundo de afuera" en que se presenta la obra obviamente ha cambiado, la "situación de crisis" o de urgencia que afecta a las cuatro protagonistas de "Tres Marías y una Rosa", cuyos maridos han quedado cesantes durante la dictadura (solo el de una de ellas tiene trabajo, pero le pagan con juguetes "patulecos" que no pueden vender), persiste actualmente en Chile. Y recordemos que es, precisamente, en situación de crisis, como dice Kobena Mercer, que la identidad, motivo también presente de muchas maneras en esta obra, se convierte en un tema significativo ${ }^{3}$. Hoy perduran los problemas económicos, ligados también a otras dificultades, como la educación, la salud, la droga y la pobreza.

La obra evidentemente presenta temas "vigentes", como la cesantía, la crisis económica, las brechas entre clases sociales, la solidaridad, el trabajo. Sin embargo, leer "Tres Marías y una Rosa", ver la puesta en escena de hace treinta años (a través de un video registrado por la Universidad de York), revisar las críticas y comentarios de la prensa de la época, intentar entenderla en dicho contexto y luego apreciarla hoy en la sala Antonio Varas del Teatro Nacional y ser testigos de la reacción de un público risueño y mayoritariamente joven, nos lleva a plantearnos una serie de otras interrogantes ${ }^{4}$. Entre ellas, ¿qué ha cambiado y qué se ha mantenido del

2 Las citas y opiniones de Raúl Osorio son parte de una entrevista personal realizada el 15 de julio de 2009.

3 "La identidad sólo es un tema cuando está en crisis, cuando algo que se supone fijo, coherente y estable es desplazado por una experiencia de duda e incertidumbre" (Cit. en Larraín 160).

4 Osorio asegura, luego de la aplicación de algunas encuestas, que el público que asiste (al igual que en la puesta en escena de fines de los 70), es muy misceláneo, de distintas comunas, edades, ocupaciones y clases sociales. 
contexto original? ¿Cuál es, realmente, el "contexto original”, pues puede que existieran también elementos residuales de otros tiempos? En palabras de Raymond Williams, ¿qué es lo residual, lo dominante, lo emergente? ¿Qué se gana/ pierde con esta reposición? ¿Cómo se percibe (se "lee")? ¿Existen imágenes sociales residuales de la dictadura? ¿Qué representaba la obra hace 30 años y si esto ha cambiado hoy?

Tantas preguntas nos hacen volver y repensar el tema de las arpilleras y sus creadoras y bordadoras (las arpilleristas) y cómo éste es a/bordado en la obra. Según Osorio, este tema es solo anecdótico (y así parece en el montaje, donde no hay mayores referencias a este movimiento de resistencia). Argumenta que, al igual que en su primera temporada, la mayor parte del público incluso desconoce la existencia, organización e ideales de estas mujeres que, durante la dictadura militar, consiguieron organizarse no solo para subsistir económicamente, sino para hacerlo a través de la creación de arpilleras, estas telas que contaban y denunciaban sus propias historias (y las de otras personas que también eran sus propias historias, como lo van descubriendo las protagonistas en el transcurso de la obra), que se organizaron así también para realizar otras actividades de denuncia y protesta y a través de su arte lograr además mantener viva la memoria.

A la luz (o ausencia de luz) de la época en que surgió la obra es comprensible que muchos temas como éste solo se presentasen a través de breves pistas apenas mencionadas, únicamente asibles por un espectador informado y atento. Por ejemplo, en lugar de la Vicaría de la Solidaridad-que patrocinaba estos talleres de arpilleristas-se habla de "la Central"; asimismo, se menciona tangencialmente el exilio, los allanamientos, las detenciones y

5 "En la producción cultural las condiciones de dominación están por lo general claras en ciertas instituciones y formas dominantes. Estas pueden presentarse como desconectadas de las formas sociales dominantes, pero la eficiencia de ambas depende de su profunda integración. Los dominados por tales formas las consideran a menudo más como formas naturales y necesarias que formas específicas, mientras quienes dominan, en el área de la producción cultural, pueden ser conscientes de forma bastante desigual de estas conexiones prácticas, en una gama que va desde el control consciente (como el de la prensa y la radio y la televisión), pasando por varios tipos de desplazamiento, hasta una presunta (y por tanto dominante) autonomía de los valores estéticos y profesionales (...). Pero se da también el caso de que en la producción cultural, tanto lo residual -la obra realizada en sociedades y épocas anteriores y a menudo diferentes, pero todavía accesibles y significativas- como lo emergente -la obra de diversos tipos nuevos- son accesibles como prácticas" (Williams, Sociología 189-190). 
el significado de las arpilleras como movimiento de resistencia. No obstante, creo que esas mismas pistas hoy pierden valor al no profundizarse en ellas y tampoco ser capaces de revivir en la sala de teatro el ritual, la transgresión, la risa nerviosa, la complicidad, el temor y la solidaridad de poder compartir, mencionar, insinuar, actuar, temas contingentes que estaban vedados, censurados, invisibilizados. Es decir, sostengo que si bien en su época el montaje fue exitoso en instalar discursivamente significantes y significados que ponían en duda el mensaje oficial (a través de metáforas, elipsis y otros recursos), con la voluntad clara de incidir en su entorno, hoy su discurso (al eludir lo esencial que, a mi modo de ver, se relaciona especialmente con la resistencia, simbolizada en las arpilleras), más bien se funde con el hegemónico. Se reproduce así la dominación y sus consecuencias (la lucha se da, entonces, en lo simbólico; también en lo simbólico), convirtiendo este símbolo de resistencia en algo anecdótico, institucionalizado, mercantilizado, olvidado. Es decir, concuerdo con Osorio en que este remontaje de "Tres Marías y una Rosa" puede hacernos más conscientes del presente, pero creo que lo que nos "muestra" de nuestra adusta época es la primacía de una lógica de mercado que incluso nos ha llevado a mercantilizar el pasado (y sus símbolos).

\section{EL CONTEXTO/ LAS ARPILLERAS}

La palabra "obra" evoca algo en construcción. Puede referirse, entre muchas posibilidades, a un edificio aún en sus cimientos o a una obra de arte que, por supuesto, es algo abierto, tanto para su creador como en la particular "construcción" que tiene con quien interactúe con ella. "Las obras no se acaban - decía Valéry-, se abandonan" (Cit. en Geertz 15). Por eso, cuando hablamos de una obra de teatro no debemos fijarla, ni siquiera pensar que se repite tal cual día tras día, porque ninguna función de una misma obra es igual a otra. Cambia la interpretación, cambia el público, cambia el contexto. Para qué decir si pasan tres décadas y vuelve a montarse una obra como "Tres Marías y una Rosa" que, cuando nació, en plena dictadura, fue muy "exitosa” (¿qué es el éxito?) Tal vez sería más certero decir que se presentó durante un año y medio a tablero vuelto, que recibió varios premios (Premio a la Mejor Obra de 1979 de la empresa de seguros Chilena Consolidada -nombre en sí sospechoso en un mundo también en construcción-y Mejor Actriz de Reparto, a Soledad Alonso), y luego realizó una gira alabada por 
la prensa internacional por diferentes ciudades de Brasil, Canadá, Estados Unidos, Inglaterra, Holanda, Suecia, Alemania y Francia. Como todo -como cualquier construcción, como cualquier acontecimiento-, una obra se inserta, entonces, en un contexto histórico determinado (también "en construcción": flotante, móvil, vivo), en el que "actúa" y el cual, a la vez, la determina y la enmarca.

En un contexto tan particular como el de la dictadura en Chile, el teatro y sus "obras" tuvieron un papel fundamental. Como explica Diana Taylor, en The Archive and the Repertoire: Performing Cultural Memory in the Americas, cualquier performance es simultáneamente real y construida (3), y creo que el teatro de esa época entraría, entonces, en esta categoría. Si bien las obras hablaban muchas veces de una historia inventada (aunque se basaran en la vida real), su presentación en un contexto determinado tuvo un efecto real de "agenciamiento" (agency) que no puede ser pasado por alto ${ }^{6}$. Es decir, las representaciones no solo muestran o reflejan una realidad (mímesis) sino que ayudan a construirla. Porque el teatro en dicho contexto fue en sí un "actor" muy importante para comenzar a denunciar las inequidades, los miedos, las frustraciones, originadas en esa época; para comenzar a hablar de aquello que nos preocupaba y apesadumbraba, para reunir a la gente, para lograr que muchos vencieran o intentaran vencer el miedo y "actuar", pero no solo sobre el escenario de una sala de teatro sino en el "escenario" nacional. "Desde luego, en todas las sociedades el teatro es un componente esencial tanto del control político como de la protesta e incluso de la rebelión" (Thompson 26). Es decir, poco a poco el teatro de la época -pese a la persecución de muchos teatristas, la censura, la autocensura, los exilios-fue negociando, utilizando los intersticios que le dejaba el poder, para convertirse en un espacio (y una fuerza) que puede ser leído como de libertad y resistencia. María de la Luz Hurtado, en el artículo "Teatro chileno en democracia: historicidad y autorreflexión", explica:

Durante los diecisiete años de Gobierno Militar liderados por Pinochet, la resistencia cultural se centró fuertemente en el teatro, ya que el cine, la televisión y la industria editorial estaban sujetos a férrea censura. El teatro acompañó muy cercanamente la discusión

6 Grínor Rojo, en Diez tesis sobre la crítica, define el "agenciamiento" como "la capacidad que a los seres humanos nos faculta para actuar en el mundo no reproductiva sino productivamente" (105). 
crítica, la denuncia, la expresión de una sensibilidad herida por los rotundos cambios culturales y de proyecto social que vivía el país. A la distancia, se ve como una etapa heroica, en la que se corrían, a la vez, riesgos personales y riesgos artísticos, acompañados por un público que celebraba y compartía esta actitud. Había un "sentido" que unía el quehacer con la propia identidad (7).

Es lo que ocurrió con "Tres Marías y una Rosa” y otras puestas en escena, especialmente de grupos de teatro profesional independiente que, sobre todo desde 1976, comenzaron a montar obras nacionales que compartían lo que, en la conceptualización de Raymond Williams, podría denominarse una cierta "estructura de sentimiento"?.

Creo que debido al peculiar contexto en que nació "Tres Marías y una Rosa", el tema de las arpilleras (actividad que surgió también en dicha época), es central en la obra, más allá de la importancia que se le dé en cada puesta en escena particular. Sobre todo, vista con la distancia con que podemos releerla hoy, a tres décadas de su estreno. En una época marcada por el terror, la censura, la autocensura y el miedo, el teatro, como había adelantado, tuvo un papel fundamental, para denunciar, juntar a la gente, en fin, como vehículo de resistencia frente a un poder que intentaba acallar la voz de aquellos a quienes pretendía marginar (e incluso excluir). Si este vehículo de resistencia además nace y habla o hace referencia a la resistencia (a través de las arpilleras y arpilleristas que fueron símbolo de ésta, generando, como las Madres de la Plaza de Mayo, en Argentina, nuevas estrategias simbólicas para intentar cambiar las estructuras del poder dominante y opresor), el tema no puede ser insignificante ni solo anecdótico.

Es decir, a la resistencia propia del teatro de la época, que lograba aunar a la gente y darles también un espacio para hablar y discutir -en una sociedad donde cualquier agrupación de personas era vista como "peligrosa"-, se suma el hecho de que aquí se a/borde un tema que representa en sí la resistencia (en terminología de Williams, lo "emergente", es decir, una ruptura respecto

7 Para Williams, la estructura de sentimiento es una hipótesis cultural que permite leer estrategias simbólicas y de representación a partir de la forma en que fueron vividas, experimentadas. Es decir, de una experiencia social que todavía está en proceso. En entrevista con Beatriz Sarlo, sostiene: "mantengo el concepto de estructura de sentimiento para describir algo que sucede específicamente en las obras de arte, en la literatura: que se comunica y se realiza en un nivel diferente al de la ideología, en sistemas de atracción y repulsión, disposición de intereses, etc." (Williams, "Raymond" 13). 
a lo hegemónico). Porque al igual que los teatristas de la época, las mujeres que comenzaron haciendo arpilleras para subsistir económicamente, al alero de la Vicaría de la Solidaridad, en espacios silentes y marginalizados como los patios interiores de sus casas y sótanos de parroquias, pronto fueron denunciando a través de su trabajo (y su arte) los horrores que se vivían en Chile y organizándose para realizar otras agrupaciones y actos de protesta, como explica Marjorie Agosin en su texto Tapestries of Hope. Threads of Love $^{8}$. En éste, Violeta Morales, cuyo hermano, Newton Morales ies? un "detenido-desaparecido" desde el 13 de agosto de 1974, da su testimonio:

Nosotras, las arpilleristas, no sólo queríamos denunciar los desaparecimientos de nuestros seres queridos sino también que las personas supieran sobre la miseria de nuestras compañeras que vivían en poblaciones, y el gran abuso que los militares estaban cometiendo en nuestro país. Queríamos gritar al país sobre las horribles ofensas contra los seres humanos y sobre las agresiones que eran cometidas diariamente contra los derechos básicos de los individuos (108-9).

Así, al juntar manos, sueños, esperanzas, existencias fragmentadas o fragmentos de existencias, se reunían/ cosían/ suturaban también retazos de telas, de telas que representaban a su vez lo marginal pues eran heridas, despojos, pedazos de vestimentas usadas hasta el cansancio, lavados una y otra vez, raídos, abandonados, como estos personajes, como ya dije, en el linde, en el extrarradio de una ciudad y una sociedad que intentaba (aún hoy) mantenerlos invisibilizados, ocultos. Personajes de carne y hueso que sufren por la violenta irrupción e indiferencia del régimen que impuso un "sistema" económico neoliberal que los atañe, los empobrece y los deja aún más al margen, aislándolos, alejándolos, sin que nadie -oficialmente- repare ni se preocupe por ellos. Es lo que ocurrió efectivamente con las arpilleristas y con tantas de las historias que denunciaban, con tantos detenidos desaparecidos que aún no "aparecen" y cada vez los gobiernos se preocupan menos de ellos y de quienes los "desaparecieron". De esta manera, vislumbramos aún más el fracaso de estas telas que hablaban de las poblaciones marginales, de los comedores infantiles, de las ollas comunes, de los niños pidiendo, de las fábricas cerradas y también de torturas, de presos políticos, de detenidos

8 La mayoría (80\%, según el texto de Agosín) era de bajos recursos; muchas también, familiares de detenidos desaparecidos (18). 
desaparecidos, trabajos anónimos que pretendían dar cuenta de la realidad, denunciar, pero además mantener viva una memoria y provocar cambios en la sociedad ${ }^{9}$.

Tal vez podríamos hablar, entonces, de esta obra como "meta-resistencia", al representar la resistencia tanto sobre el escenario cerrado de una sala de teatro como al hacer efectivamente resistencia a través de esto. Y, posteriormente, quizás dar incluso otra vuelta de tuerca, al mostrar una lucha por apropiarse de esta resistencia o "meta-resistencia”, que, así como el destino de muchas arpilleras, de estar hoy en colecciones particulares o exhibidas en muros de museos, pretende fijarse, estabilizarse, convirtiendo lo que un día fue resistencia en mercancía e integrándose de alguna manera así a la misma lógica de mercado propugnada por el régimen, a la que denunciaba y contra la cual se resistía. Es lo que ocurrió quizás con obras como, por ejemplo, "La muerte y la doncella", de Ariel Dorfman, que en muchos países (aunque no en Chile) tuvo un gran éxito de público e, incluso, fue llevada al cine por el director Roman Polanski. Es decir, el tema de las arpilleras es fundamental no solo en su relación con la resistencia sino también y, vinculada con ésta, con el motivo de la mercantilización del arte (y hoy también de la memoria), como veremos a continuación, presente tanto en el desarrollo de la obra (en el texto dramático), como en la inserción de ésta en su época y escenario "real" (e igualmente "dramático").

$\mathrm{Y}$ en este tiempo y escenario real, podemos encontrar y profundizar en las tres áreas principales de tensión, conflicto y lucha que distingue el mismo Williams en Sociología de la cultura dentro de los elementos de asimetría entre producción y reproducción social y cultural en las relaciones entre cultura dominante y subordinada. Por un lado, las formas de control, tan propias de la época en que nació la obra. A su cabeza (es solo una forma de decir), la censura, que aunque sea una palabra tan rotunda, en una época igualmente taxativa, también se paseó a veces por caminos sinuosos, donde los lábiles límites entre lo permitido y lo prohibido portaban ciertas ambigüedades y caminos alternativos, márgenes móviles y poco claros (márgenes que muchas veces fueron burlados y desplazados por las manifestaciones culturales -el teatro y las arpilleras, entre otros- y su diálogo con un público ávido de desplazamientos). Estos quedaron expuestos, por ejemplo, cuando, por

\footnotetext{
9 No se firmaban por motivos obvios; en la obra, la gran arpillera es firmada como "tres Marías y una Rosa".
} 
algún percance fuera de lo estructurado, se filtró un memorándum enviado el 22 de agosto de 1979 por el Director Nacional de Informaciones, Odlanier Mena, al Ministro del Interior, expresando su inquietud frente a puestas en escena de obras -como "El último tren", "Tres Marías y una Rosa" y "Loyola, Loyola"- que, según éste, atacaban al régimen militar. Luego de un análisis de cómo se había "vigorizado el movimiento artístico-cultural de izquierda" en el país, Mena sugiere evitar acciones represivas contra estas actividades porque "las obras no tendrán 'capacidad masiva' y cualquier persecución tendría el efecto no deseado de despertar vivo interés nacional e internacional en la obra y sus realizadores". Propone entonces crear una comisión de autoridades gubernamentales y artistas para diseñar un plan que impulse creaciones de carácter nacionalista y de recuperación de los valores nacionales (Cit. en Ulibarri 33).

“Tres Marías y una Rosa" fue también acusada por el diario La Segunda -representante, por supuesto, del poder hegemónico-, de ser una "obra panfletaria" y de buscar "agitar el gallinero" (intentando quizás emular el lenguaje popular de la obra, donde sus protagonistas hablan de "apechugar", de "salir arrancando", entre otras expresiones). En la sección "TOP SECRET" del 31 de julio de 1979 señalaba además que:

La puesta en escena, que está desde el jueves de la semana pasada en la sala Del Ángel, sólo persigue desatar el odio de clases y dividir a los obreros y a la opinión pública frente a ciertos acontecimientos. Su hilo central está basado en las penosamente célebres arpilleras que mandaba la Vicaría fuera del país con escenas de fábricas cerradas, fusilamientos en masa y otros, con el único propósito de desprestigiar el proceso que vive Chile en estos momentos (7).

Por esta nota del diario La Segunda, Osorio y Benavente debieron acudir al Ministerio de Defensa a "dar explicaciones", luego de las cuales, militares de civil fueron a ver la obra y otorgaron su venia para que siguiera en cartelera.

Otro elemento de asimetría que menciona Williams es la organización del mercado. Este punto es igualmente un pivote entre el tema representado por las actrices sobre el escenario - que habla de la cesantía, de la necesidad de sobrevivir, del consumo- con el contexto actual (tanto nacional como mundial). En éste, la inserción "exitosa" (nuevamente, ¿qué es el éxito?) de un sistema capitalista neoliberal promovido por el régimen militar-bandera en ristre de la dictadura, que los gobiernos posteriores siguen ondeando al 
viento-y, por lo tanto, residual de la época en que nació la obra, ha provocado grandes brechas económicas entre los distintos sectores sociales (realidad, lamentablemente, tanto de la época en que nació la obra como de hoy en día).

Este punto no está incomunicado con el anterior (formas de control), porque la dictadura también pretendió utilizar al mercado para controlar la producción cultural. En el caso del teatro, en 1974 se abolió la Ley de Protección al Teatro Chileno y se le comenzó a aplicar un impuesto del $22 \%$ de la taquilla a los espectáculos, a excepción de aquellos que fueran considerados de "valor cultural" por el Departamento de Extensión Cultural del Ministerio de Educación. Quien fuera su director, Germán Domínguez, entrevistado por Raquel Correa, afirmó: "Todo esto es arbitrario; parto reconociéndolo: es arbitrario; depende de criterios absolutamente personales. No existen normas precisas para determinar cuándo una obra es artística y cultural. A mí me han entregado esa responsabilidad y trato de ser lo más honesto posible" (Cit. en Foxley 43). Más adelante, en la misma entrevista, explica que una obra, para contar con el auspicio de su institución, debe contener "valores positivos" y no atacar al régimen; "que haya crítica está bien, pero no crítica subvencionada" (43). En el caso de "Tres Marías y una Rosa" contaron con esta exención, regalía que en algún momento quisieron quitar, pero fue tarde debido al éxito de la obra.

El tercer tipo de asimetría que menciona Williams son las relaciones desiguales y cambiantes entre cultura "popular" heredada (sobre todo oral), siempre recuperada de alguna manera, y la reproducción estandarizada y cada vez más centralizada. Nuevamente, aquí podemos resumir esto en el tema de las arpilleras, donde se contaban las "historias" que movían, afectaban, dolían al "pueblo" y retrataban al Chile de la dictadura, empobrecido, sufrido, asustado, violentado. Cuando el régimen dictatorial se percató de esta imagen de Chile que salía hacia el exterior (como lo "informa" el artículo citado de La Segunda), organizó la fabricación de "contra-arpilleras". Las arpilleras de telas de mucho mejor calidad, bordadas a pedido de Cema Chile (Centro de Madres), la institución que creó y dirigió la esposa de Augusto Pinochet, retrataban un Chile bastante distinto, en el que primaban las imágenes de un mundo tranquilo y perfecto, donde lo importante eran los "íconos" de la chilenidad, como la cordillera de los Andes, los volantines, las fondas y empanadas; "bote manicero, parada militar, greda de Quinchamalí" (Cit. en 
Benavente 147), explica en la obra María Luisa ${ }^{10}$. Se componía así una imagen "naturalista" del país, donde la existencia se asimilaba a la naturaleza y el marasmo. Si pensamos en qué es lo chileno y resumimos nuestra respuesta en algunos símbolos como las empanadas y ciertos paisajes como la cordillera de los Andes, creo que es lícito preguntarnos si esta frágil e inestable "identidad nacional" no está "construida" sobre los endebles cimientos de la destrucción (o por lo menos “invisibilización”) de los más débiles, portadores en sí mismos de lo popular, haciéndonos pensar que tal vez sea precisamente esta precariedad, esta miseria, esta desposesión, miedo, inseguridad, parte fundamental de lo propio de la identidad nacional en el contexto en que surgió la obra (y residual hasta el día de hoy).

Este conflicto de cómo se representa Chile se repite en "Tres Marías y una Rosa", donde las cuatro mujeres que allí aparecen, integrantes de un taller de arpilleristas dependientes de la "Central", no dejan de tener controversias para decidir qué representarán en sus "obras". María Luisa, por ejemplo, aboga por una creación más libre y "artística" (aunque, en cierto momento, movida por la necesidad de alimentar a sus hijos, decide comenzar a trabajar para "una butic de Providencia", tranzando estos principios). María Ester, por su parte, hace su trabajo casi en serie, reproduciendo una y otra vez la cordillera de los Andes y los comedores infantiles. Maruja, la jefa del taller, nunca ha querido vender la arpillera que hizo mostrando el cierre de la fábrica donde su marido era dirigente sindical. Rosa, por su parte, la última en incorporarse, recibe información de las otras mujeres sobre los distintos métodos que utilizan para decidir los temas de sus arpilleras (María Luisa, por ejemplo, le aconseja cubrirse la vista y "mirar para adentro", mientras María Ester le explica que debe repetir la cordillera de los Andes y los motivos de población). Pero finalmente, cuando todas juntas fabrican sobre el escenario la gran arpillera que les encarga el párroco, optan por el motivo del Juicio Final, más simbólico y representativo de lo que las aflige y mueve (aunque coloreado todo a grandes brochazos metafóricos, sin entrar en detalles, probablemente para eludir las reacciones y el control del poder hegemónico).

10 Todas las citas de la obra son de la versión de "Tres Marías y una Rosa", publicada en el libro Teatro Chileno, de David Benavente, Ediciones ChileAmérica - CESOC, 2005. 


\section{CRÍTICA OBLICUA}

Los teatristas de la época en que nació "Tres Marías y una Rosa" debieron utilizar distintas estrategias discursivas y "performativas" para sortear/ hablar de lo prohibido (lo que James Scott en Los dominados y el arte de la resistencia denomina el discurso oculto), comunicar y provocar o intentar incitar cambios en sus respectivos "escenarios" nacionales. Para esto, en el caso de "Tres Marías y una Rosa", el motivo de las arpilleras es fundamental. A través de éstas no solo se "habla" de temas como la cesantía, el cierre de fábricas, los allanamientos, las detenciones, la pobreza, las formas de organización que comenzaban a surgir, entre otros, sino que además se "performan" en el escenario mismo, en el cuerpo de las actrices, cambios significativos, que tienen que ver con crear (contra el ambiente de destrucción que primaba en el país) y "performar" una posible transformación; una manera de revertir aquello que a veces se daba por sentado e inamovible, llevando así un mensaje esperanzador, de cambio posible, a los espectadores. "Arrodillaos, moved los labios en oración y creeréis", dijo Pascal (Cit. en Althusser 23).

El dramaturgo de la obra, David Benavente, repitió hasta el cansancio a fines de los 70, cuando se estrenó "Tres Marías y una Rosa", que no se trataba de una pieza feminista, pues él no lo era. Sin embargo, es la historia de cuatro mujeres quienes, debido a las vicisitudes que experimentan, en especial, por las carencias económicas (explícitamente), pero también a necesidades de agrupación, solidaridad, expresivas (de manera más tácita), se van empoderando (de hecho, en la versión original comienzan muy agachadas y van poco a poco irguiéndose), adquieren fuerza, creatividad, valor y logran revertir su destino y salir adelante (si bien aguantan la violencia de sus parejas, hablar de ello es un primer paso para un cambio). Para ahondar en esto es interesante contrarrestar la imagen social de la mujer propugnada por el régimen militar con aquella que presenta la obra y luego repensarla hoy en día, cuando "Tres Marías y una Rosa" se vuelve a poner en escena. Los militares abogaban porque la mujer, centro de la familia - célula de la sociedad-, fuera "patriota", estuviera en su casa preocupada porque los "suyos" no participaran en política (a ella le correspondía el "control", especialmente de sus hijos, para que éstos no se convirtieran en "extremistas", es decir, opositores al régimen). Ella no tenía un trabajo remunerado. De hecho, la "voluntaria" de Cema Chile era la concreción de este ideal de mujer, una mujer que no se movía por afanes de lucro o de consumo y se entregaba "a la Patria". Algunas 
de estas ideas pueden verse, por ejemplo, en este aviso que apareció el 3 de enero de 1978, en el diario La Segunda, llamando a las mujeres a votar a favor de la "legitimidad" del régimen dictatorial en el referéndum que se llevaría a cabo al día siguiente:

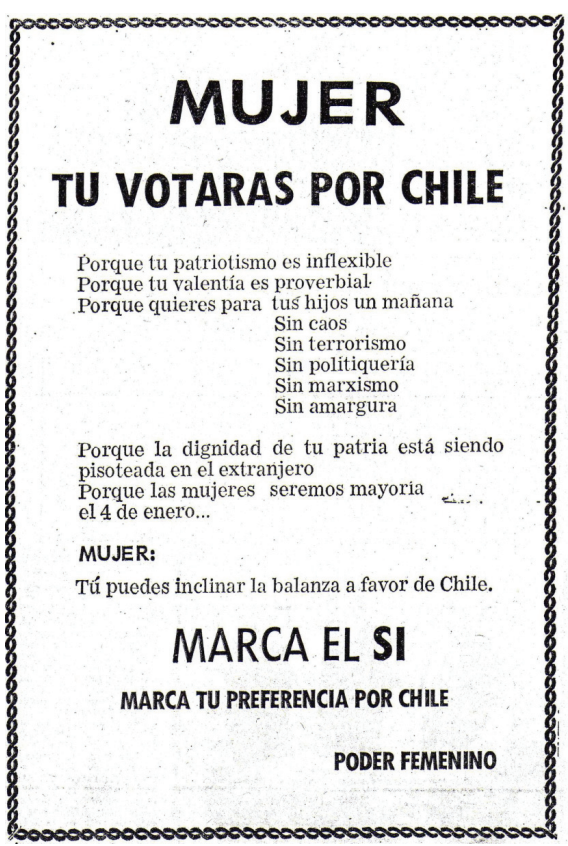

En la transmisión de estas imágenes sociales, el cuerpo tuvo un papel fundamental. Este fue utilizado tanto por el poder hegemónico dictatorial para tatuar, comunicar y difundir mensajes (de "limpieza", potestad, terror, moral, etc.), como por la resistencia (donde el teatro es solo uno de los ejemplos posibles). Para los militares, el cuerpo es muy importante y, por lo mismo, vehículo significativo para transmitir este imaginario. En Chile, por ejemplo, los pulcros uniformes, las ordenadas paradas militares, el desfile de cuerpos cuidados y venerados era exhibido para fomentar aún más la conciencia del contraste entre este país "limpio", acicalado, saludable, con aquellos habitantes -casi "sub habitantes"-, sucios, descuidados, desharrapados, chascones -incluso "enfermos"-y, como los borda María Luisa, "hilachúos". A través de señales inscriptas también en el cuerpo (el cuerpo individual como sinécdoque del cuerpo social), las dictaduras impusieron mensajes de terror (herencia de colonialidad) para promover estas imágenes y difundir estereotipos de aquellas que las desafiaran.

En "Tres Marías y una Rosa", las cuatro mujeres (así como las arpilleristas de la época) deben obviar en parte lo que se espera de ellas y organizarse para trabajar y traer dinero a la casa, en un oficio que, no obstante, les permita continuar cerca de sus familias. Encuentran una manera no solo de ser productivas, sino también un arte, para expresarse, hablar de lo que les pasa, lo que les duele, lo que sueñan; una forma de denunciar, de actuar, de resistir. Y logran así también revalorizar un tipo de labor doméstica que antes había sido vista como marginal. 
El control sobre los cuerpos (su "disciplinamiento") aparece también constantemente en la obra a través de la violencia que Roman ejerce en María Ester y de la cual ella presenta las huellas físicas arriba del escenario. Pero la violencia en su doble dimensión -evidente y simbólica- que sus "parejas" ejercen sobre estas mujeres (y ellas mismas tienen también incorporada y transmiten, como cuando María Luisa le dice a Maruja que "hay que saber ponerse los pantalones pa'ser jefa y tomar decisiones" (128), asumiendo que la autoridad es un atributo masculino), va de la mano con la violencia del propio ambiente inhóspito ${ }^{11}$. En éste, el hambre y la cesantía (en general, la opresión latente) también trascienden lo físico, al terreno de lo simbólico, en un ambiente tan universalmente adverso que las agobia hasta que son capaces de reunirse, de organizarse, de trabajar juntas, de ser solidarias y crear. Una creación donde pueden hablar y "performar" aquello que les duele, que rechazan, que no quieren, que piensan, que anhelan.

Creo que existe un paralelo también entre la reconstrucción o reaceptación y revaloración del cuerpo femenino con la reconstrucción del cuerpo social, también reprimido, violentado, cansado, sufrido. Sostengo, por otra parte, que en este proceso, es de vital importancia reparar nuevamente en el concepto de performance, el que Richard Schechner define como "comportamiento dos veces comportado" o "twice behaved behavior" (28). Dos escenas son fundamentales para ver cómo, a través de "performar" ciertas ideas, creencias, pensamientos; gracias a repetirlos una y otra vez, estas mujeres se van irguiendo no solo físicamente, sino recuperando su protagonismo, convirtiéndose en sujetos autónomos activos de su propia vida, así como de la de sus barrios y de la de su país. La primera que quiero destacar es la escena del matrimonio. En ésta, las mujeres utilizan las telas que les ha dado el párroco como materia prima de la arpillera gigante, para disfrazarse y simular el matrimonio de Rosita. Exagerando los roles de género, aprovechan la instancia para "jugar", decir y "actuar" lo que no les gusta, lo que quieren cambiar:

11 Pierre Bourdieu define la violencia simbólica como una "violencia amortiguada, insensible, e invisible para sus propias víctimas, que se ejerce esencialmente a través de los caminos puramente simbólicos de la comunicación y del conocimiento o, más exactamente, del desconocimiento, reconocimiento o, en último término, del sentimiento" (11-12). 
MARÍA ESTER (representando al cura): "Señora Rosa Martínez, ¿acepta seguir a este hombre en el dolor, la adversidad, la desgracia, la miseria, el hambre y los terremotos?"

ROSITA: No.

MARÍAESTER: “¿Acepta que la cachetée, que le ponga el gorro, que la llene de chiquillos, que no traiga plata pa' la casa, que llegue curao?"

ROSITA: No.

MARÍA LUISA: ¡Así me gusta!

MARÍA ESTER: “¿Y usted, don Rafael, promete solemnemente ante este altar sagrado no cachetearla, no ponerle el gorro, no llenarla de chiquillos, no llegar curao, y traer plata pa' la casa?"

MARUJA: ¡Bravo, señor cura! ¡Otra vez, señor cura! ¡Otra vez!

MARÍA ESTER: “¿Promete que no le va dar todas las noches con la custión, porque aburre también?"

MARÍA LUISA: ¡Que prometa! ¡Que prometa!

MARÍA ESTER: “¿Promete pedirle el favor solamente cuando ella tenga deseos?"

TODAS: ¡Prometido!

MARÍA ESTER: ¿Promete, después de ocurrido el hecho, hacerle por lo menos un cariñito?

TODAS: ¡Sí! ¡Sí! ¡Sí!

MARÍA ESTER: "Entonces, en ese caso..."

TODAS: ¡De nuevo! ¡De nuevo!

MARÍA LUISA: Pídale que le ayude a educar a los cabros, señor cura.

MARUJA: Y que le ayude a arreglar la casa, también.

MARÍA LUISA: $Y$ a no enojarse porque hace arpillera.

ROSITA: Quedarse cuidando a los chiquillos.

MARÍA LUISA: Comprarle lavadora, pa' que no eche los pulmones lavando.

MARUJA: Claro! Si no hay que dejarse atropellar.

ROSITA: Porque se aprovechan de una.

MARÍA ESTER: Pa' eso están los derechos de la mujer.

ROSITA: ¡Una también es persona!

MARUJA: No hay que aguantarles ni la puntita de ahora pa' adelante.

Y si bien el ambiente (y la esperanza de transformación que conlleva) se rompe cuando el Negro (el marido de Maruja) la llama desde la calle para que lo ayude a bajar unos paquetes, terminándose la meta-ceremonia (teatro 
en el teatro) y recordándonos que era solo un simulacro, un juego, ya han dado un paso importante hablando de lo que las molesta, reconociendo lo que quieren cambiar, diciéndolo (repitiéndolo) y actuándolo, representándolo, "performándolo", un primer impulso para transformar lo que las incomoda y rechazan ${ }^{12}$. "Estuvo linda la fiesta, ¿ah?" (163), dice luego Rosita, dando a entender lo importante que es para estas mujeres (y otras/os) seguir representando estos rituales, pero no como les son asignados, entregados, fijados por la Iglesia o cualquier otra institución, sino re/pensados, re/ significados de acuerdo a las necesidades y deseos de los sujetos ${ }^{13}$. Repetir estos rituales, de esta forma, modificándolos y re/significándolos es, así, una manera de "performar" la libertad, los derechos, en fin, pasos necesarios para lograr un "agenciamiento".

En la misma escena, para disfrazar a Maruja de hombre -"no se puede hacer de novio vestida de mujer" (159), dice Ester-, deciden que deben colocarle además "el pirulo", para lo cual utilizan una bobina de hilo, simulando un pene enhiesto. Subrogan así la percepción que sienten (no sin fundamentos) que los hombres tienen de las mujeres para, esta vez, ser ellas quienes los perciban como objetos sexuales. Pretenden así apropiarse o subvertir el rol/espacio del otro y señalar una posible resolución a través de los juegos, pero también en la trama, donde los hombres temen perder sus espacios, su "control", al quedar desempleados, al convertirse ellas en "proveedoras". Esto choca con la imagen social que los militares tienen de las mujeres (lo femenino es lo poco viril, lo indeseable, lo pasivo), así como el machismo y misoginia propia de la sociedad (de entonces y hoy, donde la violencia intrafamiliar es un tema absoluta -y lamentablemente- vigente). La necesidad de "performar el género", en este caso, es impulsada por las carencias económicas y el desempleo de los hombres ${ }^{14}$. Estos últimos tampoco

12 El juego, para muchos autores, reviste especial seriedad. Para el psicoanálisis, por ejemplo, el juego de personajes, junto a la satisfacción directa o indirecta de impulsos eróticos infantiles, sirve de defensa contra el miedo y la angustia.

13 “¡Cómo va a venir el Papa, si vive en Roma, pues, Rosita!” (175), dice más adelante Maruja, dando a entender lo desamparados y abandonados que están y se sienten estos personajes.

14 Como dice Judith Butler: "si el cimiento de la identidad de género es la repetición estilizada de actos en el tiempo, y no una identidad aparentemente de una sola pieza, entonces, en la relación arbitraria entre estos actos, en las diferentes maneras posibles de repetición, en la ruptura o la repetición subversiva de este estilo, se hallarán posibilidades de transformar el género" (297). 
pueden adaptarse fácilmente a dichos cambios, por lo que golpean a "sus" mujeres y, se avergüenzan del trabajo de ellas, lo que no es de extrañar si consideramos que su identidad individual la han construido (al igual que el imaginario militar), enfrentada o en contra de lo femenino. Si bien se han experimentado cambios en este sentido en los últimos años, especialmente luego de la dictadura militar, el problema de fondo persiste, vinculado a una mentalidad residual propia de una sociedad "patriarcal" o "androcéntrica" que hemos heredado.

La fabricación de la gran arpillera es otra oportunidad "performativa" importante para que estas mujeres (y a través de ellas, el público del teatro, por lo menos, el original) representen, hablen y actúen sobre aquello que las incomoda para, de alguna manera, comenzar un proceso de cambio, de transformación (vinculada, claro, con la resistencia). Pero, en este caso, más allá del género (femenino y del osnaburgo). En el mismo escenario, las actrices van creando una arpillera real, discutiendo su tema y fabricándola entre todas (lo que poco a poco las va uniendo, haciéndolas más solidarias, pese a muestras anteriores de un marcado individualismo). Así se evidencia el potencial transformador de la acción de estas mujeres en una sociedad que les niega incluso la posibilidad de reunirse y de hablar de ellas mismas. Mientras trabajan, bordan la arpillera, a la vez que reconstruyen sus propias historias (igual que las arpilleristas de la época que en la tela dejaron bordada, entre otros motivos, a la familia -"deshilachada"- que el gobierno militar muchas veces les usurpó). A través de la composición de la arpillera gigante sobre el Juicio Final, estas mujeres aprovechan también la oportunidad para expresar sus rabias, frustraciones, deseos, travesía que conduce al "agenciamiento".

Aquí acusan nuevamente el machismo de sus parejas, las inequidades entre pobres y ricos, la necesidad de justicia. La posibilidad de a/bordar como ellas quieran esa "obra" (la arpillera gigante), les permite elaborar sus discursos sobre, por ejemplo, la injusticia. "Porque el juicio chileno tiene que darse" dice parte de la cueca que inventan para la inauguración de la capilla, donde irá su trabajo; "todo gratis", quieren escribirle, por otro lado, a las fondas que deciden agregar en el cielo; consideran también la posibilidad de colocar a sus hombres en el infierno... De esta manera descubren su capacidad creativa y transformativa; ven que pueden denunciar, organizarse y generar dinero en un contexto adverso. Así el arte, su arte, el de las arpilleras, se opone y resiste al contexto de la época y a la representación de las mujeres que promovía el régimen. 
Por supuesto que pueden abstraerse muchos motivos actualmente vigentes, vinculados sobre todo con el lugar de la mujer, el trabajo, la dignidad, entre otros. No obstante, creo que al presentar hoy esta obra, que nació demasiado ligada e influida por su contexto, tal cual fue concebida en una época en que el arte y la sociedad eran silenciados y vigilados, se pierde algo esencial. Y este "algo" tiene que ver con el tema de las arpilleras. El símbolo de la arpillera como aglutinador de todas estas temáticas, de la resistencia, de las mujeres que se unen, de la solidaridad, del reflejo y necesidad no solo de mostrar sino también de vencer y torcer esta realidad, no es algo evidente cuando leemos o vemos este montaje. Las arpilleras más bien se plantean como una solución a los problemas económicos de estas mujeres. Únicamente se alude a la arpillera que hizo Maruja, representando el cierre de la fábrica y a un intento fallido de María Luisa de vender una tela sobre el Juicio Final, hasta que se re-únen (María Luisa y María Ester se habían desligado un tiempo del taller para colaborar en otro) para crear la gran arpillera que les pide el párroco. Optan por el tema de la arpillera que María Luisa no pudo vender, el Juicio Final, para a través de él hacer mayores referencias, aunque siempre metafóricas, a la realidad de la época que denunciaban. Sin embargo, queda la idea de que se trataba solo de un caso específico creado por estas mujeres concretas, en esta obra puntual. Que no haya más referencias o referencias más directas a los temas y acciones de las arpilleristas se entiende en el clima de miedo y opresión que primaba en 1979 (por eso la obra pudo ser catalogada de "cultural" y exenta de impuesto). No obstante, creo que esto mismo hace que hoy el tema pase a un segundo plano, relegado a lo anecdótico y, por lo tanto, se vaya difuminando, perdiendo, borrando, un contenido esencial, lo que, además, habla muy mal de nuestra sociedad, guiada por la lógica de mercado que "exitosamente" (el siempre relativo "éxito") impuso el gobierno militar, la cual ha absorbido incluso la resistencia y la memoria, simbolizadas en las arpilleras.

Según el académico Juan Villegas, existen dos lecturas posibles para un texto dramático que tienen que ver con la experiencia de mundo del lector. Por un lado, está la lectura reconstructora, que aspira a recomponer el horizonte de expectativas del destinatario original. Por medio de éste, sería posible aproximarse al signo del texto en el momento de su producción. Existe también la posibilidad de una lectura actualizadora, que prescinde del potencial lector original o de los códigos contemporáneos a la producción del texto, "deshistoriza" el texto y lo "lee" dentro del espacio cultural y el tiempo del lector (130-133). Creo que en la re/posición de "Tres Marías y 
una Rosa" no se priorizó lograr ninguna de estas lecturas (lo que viene a ser, más bien una a-posición que, no obstante, no puede eludir la posición). Al mantenerse intacto el texto que es, en sí, elusivo (producto de la época en que surgió), no se opta por profundizar en ese contexto y, por lo tanto, se pierde mucho de su esencia. Esta pérdida se vincula especialmente con la resistencia que representa (simbolizada en las arpilleras), la cual más bien se transforma en un "ícono", no muy distinto a los botes maniceros y la greda de Quinchamalí, mencionados en el texto dramático. Y es éste el que atrae en gran parte al público interesado en ver una obra tan importante, símbolo del teatro en dictadura, pero que, finalmente, abandona la sala con la sensación de haberse reído, pasado un buen rato y sin entender, quizás, qué fue lo que se perdió.

\section{A MODO DE CONCLUSIÓN}

Una vez supuestamente "recobrada la democracia", la Vicaría de la Solidaridad consideró terminado su trabajo. Los talleres de arpilleristas perdieron el patrocinio de la Iglesia y fueron desmantelados en 1992. Aunque algunas de estas mujeres continuaron fabricando arpilleras solas en sus casas o en una pieza de la iglesia metodista en el centro de Santiago, su trabajo quedó enmarcado en una época en la cual incluso, como lo hace notar Osorio, también fueron bastante "invisibilizadas". Y lo continúan siendo hoy, dando testimonio con sus vidas y trabajo de algo más que borró la mercantilización de una sociedad deshumanizada por el triunfo del capitalismo liberal y la sociedad de consumo.

A través de su arte intentaron subvertir el orden de cosas impuesto por el poder hegemónico, su marginalidad, así como también denunciar e intentar cambios en la época de la dictadura y, de la mano con esto, mantener viva la memoria. Pero no lo lograron, como lo demuestra la reposición de "Tres Marías y una Rosa", donde este tema se reduce a lo anecdótico y se fija, haciendo que el público se quede en el humor, dejando pasar la oportunidad de hablar hoy del pasado reciente que nos marcó y persigue, aunque intentemos evadirlo y esconderlo. La misma lógica del mercado que las hizo nacer para subsistir y denunciar, las absorbió, las pisoteó, las sepultó, convirtiéndolas en algo circunstancial e irrelevante, en algo olvidado (aunque se intente la apropiación, eso sí, de esta anécdota, como de "lo resistente"), porque vivimos en una sociedad donde muchos parecen querer olvidar. Así como en el pasado 
las arpilleristas fueron víctimas de la violencia de la época (la necesidad de anonimato, la censura, el temor), hoy lo son del olvido.

Este olvido se explica, según Idelber Avelar, dado que la memoria en tiempos de mercado busca siempre sustituir, reemplazar (como la metáfora). Este autor dice que, al mercantilizar cada rincón de la vida social, los regímenes autoritarios instauraron un presente que implica la negación de la memoria porque "la operación propia de toda nueva mercancía es reemplazar la mercancía anterior, enviarla al basurero de la historia" (285). Mercado y memoria entonces se anulan mutuamente: "Borrar el pasado como pasado es la piedra angular de toda mercantilización, incluso cuando el pasado se convierte también en mercancía, negándose así en tanto pasado al ofrecerse -ya convertido en mercancía reificada- como reemplazo de todo lo que en él hubo de derrota, fracaso, miseria" (285), agrega Avelar. Sin embargo, hay algo que no desaparece porque, al producir lo nuevo y desechar lo viejo, el mercado crea también restos que apuntan al pasado. Estos restos, ruinas, destrozos, los asimila con la alegoría, que siempre exhibe la marcas de su tiempo de producción (donde podemos situar, entre otros, a "Tres Marías y una Rosa" y las arpilleras). A ello se refiere también Pedro Lemebel cuando, en Loco Afán. Crónicas de Sidario, afirma:

Quizás, las pequeñas historias y las grandes epopeyas nunca son paralelas, los destinos minoritarios siguen escaldados por las políticas de un mercado siempre al acecho de cualquier escape. Y en este mapa ultracontrolado del modernismo, las fisuras se detectan y se parchan con el mismo cemento, con la misma mezcla de cadáveres y sueños que yacen bajo los andamios de la pirámide neoliberal" (23).

De todos depende acusar este olvido. "Hay una manera de contribuir a la protección de la humanidad, y es no resignarse. No mirar con indiferencia cómo desaparece de nuestra mirada la infinita riqueza que forma el universo que nos rodea, con sus colores, sonidos y perfumes" (Sábato 17-18). Para ello, es necesario mantener viva la memoria, continuar de alguna manera la lucha iniciada por estas mujeres para no tapiar "con el mismo cemento" el pasado, para no descartarlo como una mercancía en desuso en un mundo donde todo parece desechable. Es necesario intentar elevar la voz para hablar de estas historias (sus historias/ nuestras historias/ nuestra historia) que las arpilleristas fueron bordando y abordando valientemente y que hoy el mercado (residuo del control e ideario de la época en que nació "Tres Marías y una Rosa") pretende reificar y, así, adormecer, sosegar, esconder, silenciar. 


\section{BIBLIOGRAFÍA}

Agosin, Marjorie. Tapestries of Hope, Threads of Love: The Arpillera Movement in Chile. 1974-1994. Trad. Celeste Kostopulos-Cooperman. Alburqueque: University of New Mexico Press, 1996.

Althusser, Louis. "Ideología y aparatos ideológicos del Estado". Nombre Falso. Comunicación y Sociología de la Cultura. 2002-2007 http://www.nombrefalso.com.ar/index. php?pag $=81$

Avelar, Idelber. Alegorías de la derrota: La ficción postdictatorial y el trabajo del duelo. Santiago de Chile: Editorial Cuarto Propio, 2000.

Benavente, David. Teatro chileno. Santiago de Chile: Ediciones ChileAmérica - CESOC, 2005.

Bourdieu, Pierre. La dominación masculina. Barcelona: Anagrama, 2007.

Butler, Judith. “Actos performativos y constitución del género: un ensayo sobre fenomenología y teoría feminista". Debate Feminista 18/9 (1998): 296-314.

Carpentier, Alejo. "Oficio de tinieblas". Relatos. Santiago: Andrés Bello, 1999. 129.

Foxley, Ana María. “Los estragos del IVA”. Revista Hoy (14-20 de enero, 1981): 40-43.

Garretón, Manuel Antonio, et al., eds. Cultura, autoritarismo y redemocratización en Chile. México: Fondo de Cultura Económica, 1993.

Geertz, Clifford. Conocimiento local. Ensayos sobre la interpretación de las culturas. Trad. Alberto López Bargados. Barcelona: Paidós, 1994.

Hurtado, María de la Luz. "Teatro chileno en democracia: historicidad y autorreflexión". Alternativas teatrales 96-97 (Bruselas: Primer trimestre 2008): 7-12.

Hurtado, María de la Luz y José Román. T.I.T. Taller de Investigación Teatral (Serie Maneras de hacer y pensar el teatro en el Chile actual). Santiago de Chile: CENECA, 1982.

La Segunda, del 3 de agosto, 1978.

La Segunda, del 31 de julio de 1979.

Larraín, Jorge. ¿América Latina moderna? Santiago: Lom Ediciones, 2005.

Lemebel, Pedro. "La noche de los visones (o la última fiesta de la Unidad Popular)". Loco afán. Crónicas de Sidario. Santiago: Lom Ediciones, 1996. 23.

Munizaga, Giselle. La mujer, el vecino y el deportista en los micromedios de gobierno. Santiago: CENECA, 1983.

Osorio, Raúl. "Entrevista con Yael Zaliasnik”. Santiago: No publicada, 2009.

Piña, Juan Andrés. Veinte años de teatro chileno. 1976-1996. Santiago: RIL Editores, 1998.

Rojo, Grínor. Diez tesis sobre la crítica. Santiago: LOM Ediciones, 2001.

Sábato, Ernesto. La resistencia. Buenos Aires: Seix Barral, 2000.

Schechner, Richard. Performances Studies. An Introduction. Nueva York: Routledge, 2003.

Scolnicov, Hanna y Peter Holland, comp. La obra de teatro fuera de contexto. Trad. Martín Mur Ubasart. México: Siglo XXI Editores, 1991.

Scott, James. Los dominados y el arte de la resistencia. México: Ediciones Era, 2000. 
¿Re/posición? de “Tres Marías y una Rosa”: Tres décadas para a/bordar la resistencia 215

Solnit, Albert. "A Psychoanalitic View of Play”. The Psychoanalytic Study of the Child 42 (1987): 205-219.

Taylor, Diana. The Archive and the Repertoire. Performing Cultural Memory in the Americas. Durham: Duke University Press, 2003.

Thompson, Edward Palmer. "Historia y antropología". Agenda para una historia radical. Trad. Elena Grau y Eva Rodríguez. Barcelona: Crítica, 2000.

Tres Marías y una Rosa. Videocassette. Toronto: Universidad de York, 1981.

Ulibarri, Luisa. "Nuevos márgenes, espacios y lenguajes expresivos". Cultura, autoritarismo y redemocratización en Chile. México: Fondo de Cultura Económica, 1993.

Villegas, Juan. Nueva interpretación y análisis del texto dramático. Ontario: Girol Books, 1991.

Williams, Raymond. Marxismo y literatura. Trad. J.M. Castellet. Barcelona: Ediciones Península, 1998.

Sociología de la cultura. Trad. Graziella Baravalle. Barcelona: Paidós, 1994.

"Raymond Williams y Richard Hoggart: sobre cultura y sociedad". Entrevista con Beatriz Sarlo. Punto de Vista 6 (julio de 1979): 9-18. 